\title{
Study on the Influence of the Grind Percentage Over the Surface Hardness and Modulus of Elasticity of Parts Made of ABS, P6.6 and POM through Nanoindentation
}

\author{
GHEORGHE RADU EMIL MARIES ${ }^{1}$, CONSTANTIN BUNGAU ${ }^{1 *}$, DAN CHIRA*, TRAIAN COSTEA ${ }^{1}$, DANUT-EUGENIU MOSTEANU² \\ 'University of Oradea, 1 University Str., 410087, Oradea, Romania \\ ${ }^{2}$ Nicolae Balcescu Land Forces Academy, 3-5 Revolutiei Str., 550170, Sibiu, Romania
}

\begin{abstract}
This paper analyzes the indentation hardness and the indentation elastic modulus variation depending on the variation of the grind percentage of polymer, when the other factors that can influence the injection molding remain unchanged. The analyzed polymers were: acrylonitrile butadiene styrene ABS MAGNUM 3453, polyamide PA 6.6 TECHNYL AR218V30 Blak and polyoxymethylene POM EUROTAL C9 NAT. The samples that were studied had different compositions in new and grinding material. The G-Series Basic Hardness Modulus ata Depth method was used. The increase of the grind percentage of ABS (from 0 to 100 \%) leads to insignificant changes in the indentation hardness, indentation modulus, and maximum force applied to samples of tested material. The maximum hardness ( $0.137 \mathrm{GPa}$ ) of PA 6.6 is recorded in the case of the sample with $80 \%$ grind content, and the maximum hardness of POM is recorded as well in the case of the sample with $80 \%$ grind content, as being $0.215 \mathrm{GPa}$. The variation of the grind content in the analyzed samples determines changes in the evaluated parameters, depending on the type of polymer. Combining the new material with grind in proportions experimentally established for each techno polymer leads to changes in their mechanical properties.
\end{abstract}

Keywords: polymers, polyamide 6.6 (PA 6.6), acrylonitrile butadiene styrene (ABS), polyoxymethylene (POM), indentation hardness; indentation modulus

The automotive industry is considered one of the largest consumers of plastic/polymers materials. The most used techno-polymers in the manufacture of the various automotive components are: polyamides, thermoplastic polyurethanes, polyoxymethylenes, polypropylene, methyl polymethacrylate, cellulose acetate, plasticized vinyl polychloride, acrylonitrile butadiene styrene, etc. The most frequent used technology in the processing of these polymers is the injection molding.

Polyamides are substances characterized by a good dimensional stability, with a high level of rigidity (especially when they are reinforced with glass fibers); they are also resistant to compression, wear, shock and vibration; being hard materials, under the action of heat, they remain hard and tenacious, with no visible changes, up to $80-90^{\circ} \mathrm{C}[1,2]$. Adding glass fibers, the polyamides improve their flexural and tensile strength, modulus of hardness and elasticity. Polyamides have the proprieties to resist well in salted water, to be stable vs. oil, hydrocarbons, lakes, esters, ethers, weak bases, alcohols, and automotive fuels. They are considered good electrical insulators, as well. All these properties recommend them to be used in the manufacture of various articles in the automotive industry.

So, they are used for: water tanks ( glycol resistant, heat resistant, stiff, low creep), cooling module (good fatigue behavior, glycol resistant, good thermal resistance, reduces the number of used materials, stiff, good vibration behavior), water pipes, thermostats (heat resistant, glycol resistant), fuel tank, floater for carburetor, air circulation systems, cylinder head cover (heat resistant, stiff, good creep behavior, good chemical resistance to oil), housings covering engine, fans, seat structure, front air grilles structures support, structural door module, pedals and pedal cassette (behaves well in fatigue and impact, stiff), brake fluid reservoir (heat resistant, stiff, chemically resistant), handbrake lever, gearshift lever support, door handle, front wing, exterior mirrors, defroster grill, ventilation grill, fuel systems, fastening systems for wiring.

Polyoxymethylenes are opaque polymers because of their high degree of crystallinity [3] and are characterized by a good dimensional stability over a wide range of temperature. The high degree of crystallinity gives the polyoxymethylenes some general mechanical properties (especially stiffness), higher than in the case of other thermoplastics, between $50-120^{\circ} \mathrm{C}$. They are resistant to shocks, fatigue, friction and wear. Having good resistance to many organic chemical agents like aldehydes, esters, ethers, and being good electrical insulators, they are used in the automotive industry for: gearwheels, guides, housings, active organs of diesel or oil pumps, valves, floats, windscreen wipers, etc. [4].

The most important property of $A B S$, from mechanical point of view, is the resistance at shock and tenacity. ABS is stiff, wear-resistant, resistant to mechanical stress at break, has a good dimensional stability over a wide temperature range, unlimited coloring possibilities, easy injection molding [5] and it is a good electrical insulator. It is resistant to acids and weak bases and unstable to esters, ketones, ethers, and gasoline [6-9]. Applications in the automotive industry: seat components, bumpers, carcasses for electrical and electronic assemblies, roof car truck, etc.

The recovery of waste remains a topical issue in the injection molding of thermoplastic polymers. This type of waste appears in different forms: injection network, incomplete parts, plastic parts with burrs, or parts that have other manufacturing defects [10-15]. Their reintroduction in the manufacturing process (in the form of grind material) has been practiced for a very long time and leads to significant financial savings. 
The reintroduction of the grind material into the manufacturing process can be done in admixture with a new material (a kind of material that has never been injected) or there can be injected only the grind material. A series of studies have been published by our team and other researchers, in recent years, relating to the mechanical and electrical behavior of different types of polymers under different mechanical stress conditions [ 6 9,16-26].

The present paper aims to study the indentation hardness and the indentation elastic modulus variation, depending on the variation of grind percentage of polymer (injection thermoformed polymer once) of samples, when the other factors that can influence the injection molding remain unchanged.

\section{Experimental part}

Materials and methods

The materials that have been used in manufacturing the specimens, were as follows: acrylonitrile butadiene styrene type ABS MAGNUM 3453 (ABS), polyamide type PA 6.6 TECHNYL AR218V30 Blak (PA 6.6), and polyoxymethylene POM EUROTAL C9 NAT (POM), using an injection molding machine ENGEL CC 100 Type ES 80/ $50 \mathrm{HL}$, manufactured in 1995 (fig. 1) [21, 26, 27].

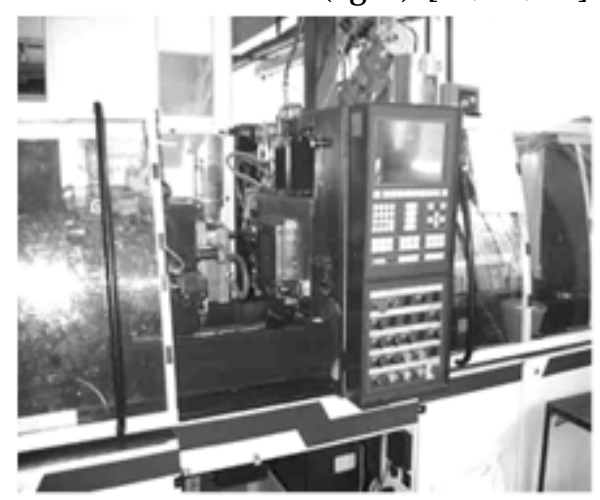

Fig.1. Injection molding machine ENGEL CC 100 Type ES 80/50 HL

A number of six samples were injected for each type of plastic material; the samples with variable grinding content are described in table 1.

Table 1

CONTENT OF THE TESTED SAMPLES

\begin{tabular}{|c|c|c|}
\hline \multirow{2}{*}{ Sample } & \multicolumn{2}{|c|}{ Sample content (\%) } \\
\cline { 2 - 3 } & $\begin{array}{c}\text { New } \\
\text { material }\end{array}$ & Grind \\
\hline 1 & 100 & - \\
\hline 2 & 80 & 20 \\
\hline 3 & 60 & 40 \\
\hline 4 & 40 & 60 \\
\hline 5 & 20 & 80 \\
\hline 6 & - & 100 \\
\hline
\end{tabular}

The injection of ABS, PA 6.6, and POM were carried out according to the parameters depicted in table 2 . The injection parameters remained constant during the whole process of injection of the six samples.

Experiments were performed atS.C. Plastor S.A Oradea, all specimens being injected and being subjected to the determinations regarding the indentation hardness and indentation modulus, within the precincts of the Laboratory of Advanced Materials, belonging to the University of Oradea (SMARTMAT: Advanced Materials Research Infrastructure, www.erris.gov.ro). The determination of the indentation modulus and indentation hardness was realized on the specimen models, with the shape and size of those presented in figure 2 .
Table 2

CONTENT OF THE TESTED SAMPLES

\begin{tabular}{|l|c|c|c|}
\hline \multirow{2}{*}{$\begin{array}{c}\text { Parameters } \\
\text { [unit of measure] }\end{array}$} & \multicolumn{3}{|c|}{ Material } \\
\cline { 2 - 4 } & ABS & PA 6.6 & POM \\
\hline Injection temperature $\left[{ }^{\circ} \mathrm{C}\right.$ ] & 230 & 300 & 200 \\
\hline Mold temperature $\left[{ }^{\circ} \mathrm{C}\right]$ & 50 & 85 & 50 \\
\hline Injection pressure $[\mathrm{Bar}]$ & 800 & 370 & 1000 \\
\hline Holding pressure [Bar] & 300 & 300 & 300 \\
\hline Injection speed [mm/s] & 30 & 100 & 20 \\
\hline Injection cycle time [s] & 43 & 26 & 32.6 \\
\hline Cooling time in the mold [s] & 20 & 10 & 15 \\
\hline Injection time [s] & 2.87 & 0.94 & 4.2 \\
\hline Holding pressure time [s] & 6 & 3 & 5 \\
\hline
\end{tabular}

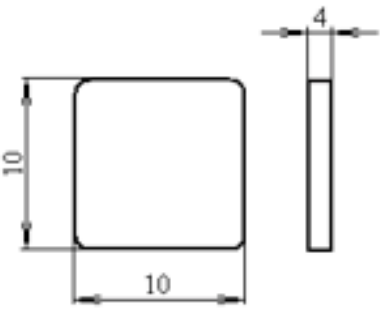

Fig.2. Specimen model for testing the indentation hardness and indentation modulus

Testing was done using Agilent Technologies Nano Indenter G200 System equipment, USA, made in 2013, in accordance with ISO 14577-1:2002 [28], through the determination method of G-Series Basic Hardness, Modulus at a Depth. The specimen on the support undergoes indentation with the help of a pyramidal-shaped indenter with a triangular base named Berkovich tip, made of diamond and presented in figure 3.

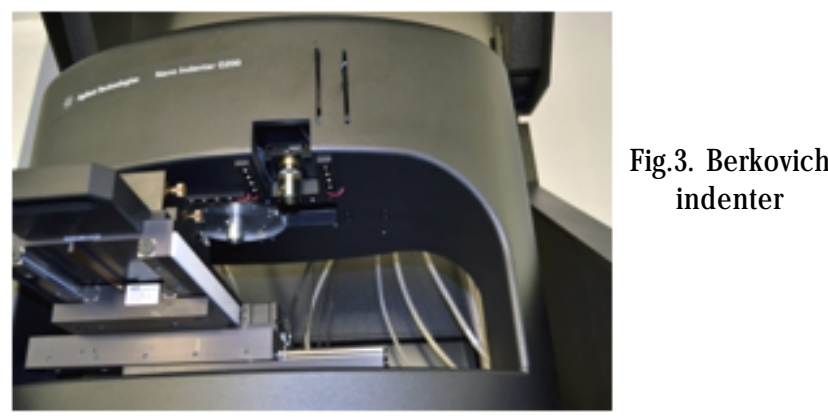

The tested area is provided as an image to the atomicforce microscope for determining the indentation hardness and indentation modulus. The force-movement variation graph obtained through indentation provides us with information on the mechanical and physical properties of the tested material. All tests were done at a temperature of $23^{\circ} \mathrm{C}$. Figure 4 sketches the testing procedure and figure 5 sketches the transversal section of the indentation.

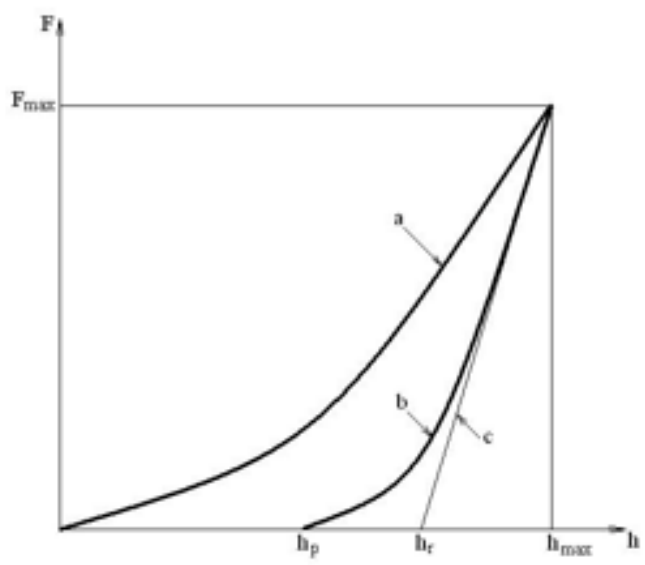

Fig.4. Schematic representation of the test procedure: $a$-application of the test force; $b$-removal of the test force; $c$-tangent to the curve $b$, at $F_{\text {max }}$ 


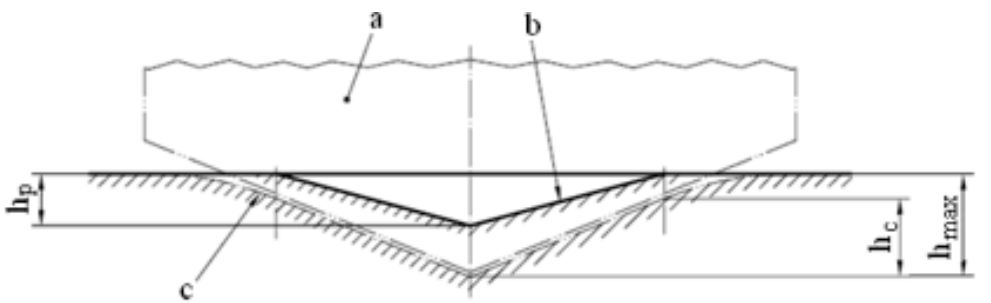

Fig.5. Schematic representation of cross section of indentation: $a$-indenter; $b$-surface of residual plastic indentation in test piece; c -surface of test piece at maximum indentation depth and test force.

Determining the indentation hardness $\left(\mathrm{H}_{\mathrm{T}}\right)$ is done using the equation 1):

$$
H_{I T}=\frac{F_{\max }}{A_{p}}
$$

where: $\mathrm{H}_{I T}$ indentation hardness, in $\mathrm{N} / \mathrm{mm}^{2} ; \mathrm{F}_{\text {max }}$ - maximum applied force, in N; $A_{p}$ - the projection (transversal section) of the contact area between the indenter and tested specimen, resulted from the force-movement variation graph, in $\mathrm{mm}^{2}$.

In the case of Berkovich indenter,

$$
A_{p}=23.96 \times h_{c}^{2}
$$

where $h_{c}$ is the depth made by indenter on the tested specimen and is calculated according to equation:

$$
h_{c}=h_{\max }-\varepsilon\left(h_{\max }-h_{r}\right)
$$

where $\varepsilon$ is a correcting factor depending on the geometry of indenter. The calculus of the indentation modulus $\left(E_{\mid T}\right)$ was done using the equations (2) and (3):

$$
\begin{aligned}
& E_{I T}=\frac{1-\left(v_{S}\right)^{2}}{\frac{1}{\bar{E}_{T}} \cdot \frac{1-\left(v_{i}\right)^{2}}{E_{i}}}, \\
& E_{r}=\frac{\sqrt{\pi}}{2 c \sqrt{A P}^{2}},
\end{aligned}
$$

where: $v_{s}$ - Poisson's ratio for the tested specimen; $v_{i}$ Poisson's ratio for the indenter (for diamond 0.07); $E_{r}$-the reduced modulus on the indenter's contact with the tested; $\mathrm{E}_{\text {- }}$-the indenter's modulus (for diamond $1.14 \times 10^{6} \mathrm{~N} / \mathrm{mm}^{2}$ ); $A^{r}$-the projection (transversal section) of the contact area between the indenter and tested specimen, resulted from the force-movement variation graph, in $\mathrm{mm}^{2}$.

When Agilent Technologies Nano Indenter G200 System was used, the computer's software automatically displayed the values of the maximum applied forces (in $\mathrm{mN}$ ), indentation hardness (in GPa), and the values of the indentation modulus (in GPa). For each of the injected samples (samples with variable grind content), a number of 25 indentations were performed and the results were expressed as mean arithmetic values. Figure 6 presents a tested POM specimen by indentation.

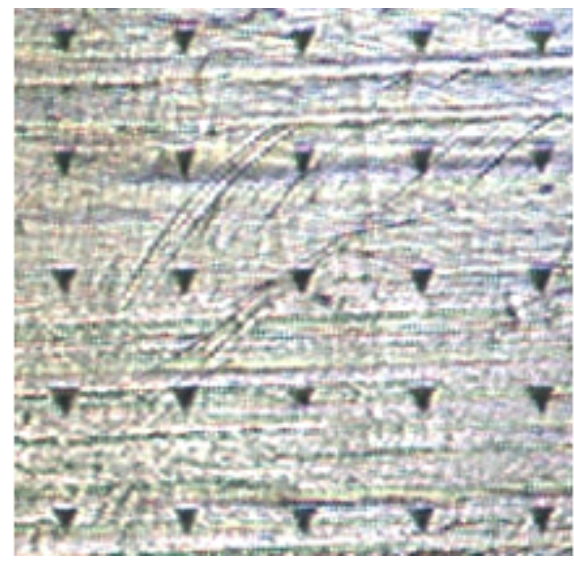

Fig.6. POM specimen tested by indentation

\section{Results and discussions}

ABS MAGNUM 3453

The results obtained, after ABS samples testing, regarding the influence of the grind percentage on the indentation hardness, indentation modulus, and the maximum applied force, showed that the sample with 80 $\%$ grind presents the maximum indentation hardness $(0.142 \mathrm{GPa})$, and also the maximum indentation modulus (2.954 GPa), without any significant variation of these parameters according to grind content (table 3 ).

\section{Table 3}

THE DEPENDENCE OF THE INDENTATION MODULUS AND THE MAXIMUM FORCE APPLIED TO ABS VS. THE GRIND PERCENTAGE

\begin{tabular}{|c|c|c|}
\hline $\begin{array}{c}\text { Grind } \\
{[\%]}\end{array}$ & $\begin{array}{c}\text { Indentation modulus } \\
{[\mathrm{GPa}]}\end{array}$ & $\begin{array}{c}\text { Maximum load force } \\
{[\mathrm{mN}]}\end{array}$ \\
\hline 0 & 2.808 & 11.801 \\
\hline 20 & 2.805 & 11.827 \\
\hline 40 & 2.923 & 12.283 \\
\hline 60 & 2.813 & 11.708 \\
\hline 80 & 2.954 & 12.490 \\
\hline 100 & 2.860 & 11.910 \\
\hline
\end{tabular}

Figure 7 shows the graphical representation of the variation of indentation hardness that depends on the grind percentage, in case of $A B S$.

ABS

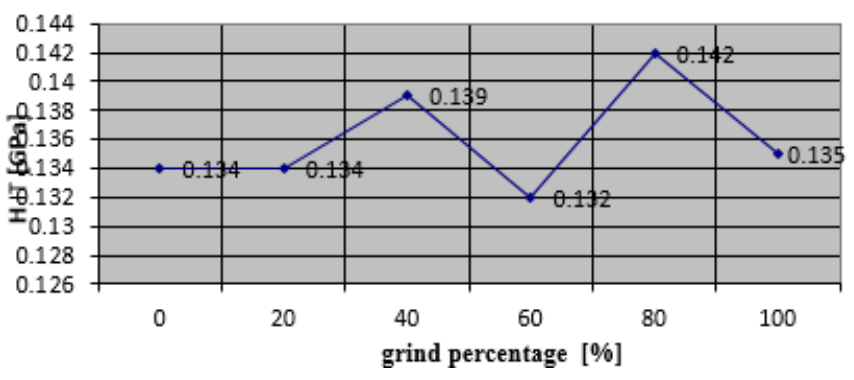

Fig. 7. The variation of the indentation hardness depending on the grind percentage, in the case of ABS

\section{PA6.6 TECHNYL AR218V30 Blak}

For polyamide PA 6.6, the maximum hardness and the maximum indentation modulus are recorded at the sample with an $80 \%$ grind content. The variation of the determined parameters, according to the combination ratio between the two materials, is presented in table 4.

Table 4

THE INDENTATION MODULUS AND MAXIMUM FORCE APPLIED TO PA 6.6, DEPENDING ON THE GRIND PERCENTAGE

\begin{tabular}{|c|c|c|}
\hline $\begin{array}{c}\text { Grind } \\
{[\%]}\end{array}$ & $\begin{array}{c}\text { Indentation modulus } \\
{[\mathrm{GPa}]}\end{array}$ & $\begin{array}{c}\text { Maximum load force } \\
{[\mathrm{mN}]}\end{array}$ \\
\hline 0 & 2.474 & 10.239 \\
\hline 20 & 2.521 & 9.791 \\
\hline 40 & 3.250 & 12.696 \\
\hline 60 & 3.043 & 11.746 \\
\hline 80 & 3.104 & 12.855 \\
\hline 100 & 2.358 & 10.224 \\
\hline
\end{tabular}




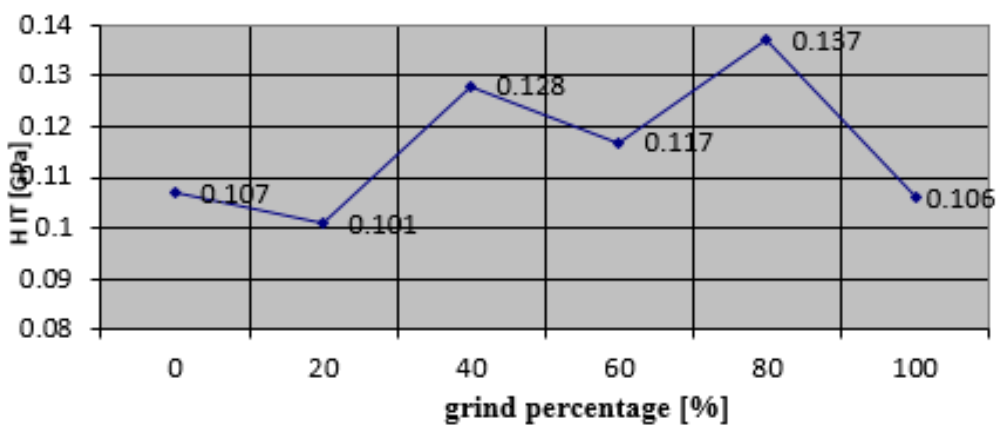

Fig. 8. The variation of the indentation hardness, depending on the grind percentage, in the case of PA. 6.6

The graphic from figure 8 represents the variation of the indentation hardness that depends on the grind percentage, in the case of PA 6.6.

\section{POM EUROTAL C9 NAT}

The results obtained in the case of POM samples, regarding the influence of the grind percentage on the indentation modulus, indentation hardness, and the maximum applied force are described in table 5. Figure 9 shows the variation of the indentation hardness, depending on the grind percentage, in the case of POM.

Table 5

THE INDENTATION MODULUS AND THE MAXIMUM FORCE APPLIED TO POM, DEPENDING ON THE GRIND PERCENTAGE

\begin{tabular}{|c|c|c|}
\hline $\begin{array}{c}\text { Grind } \\
{[\%]}\end{array}$ & $\begin{array}{c}\text { Indentation modulus } \\
{[\mathrm{GPa}]}\end{array}$ & $\begin{array}{c}\text { Maximum load force } \\
{[\mathrm{mN}]}\end{array}$ \\
\hline 0 & 3.069 & 15.280 \\
\hline 20 & 3.145 & 15.296 \\
\hline 40 & 3.282 & 15.573 \\
\hline 60 & 3.382 & 16.347 \\
\hline 80 & 3.306 & 16.732 \\
\hline 100 & 3.181 & 16.250 \\
\hline
\end{tabular}

Nanoindentation is one of the newest and modern methods of determining the mechanical properties of different materials, at a very small scale. In the nanoindentation test, the indenter is pushed into the surface of the sample; producing both plastic and elastic deformation of the material, it also indicates the variations in different parts of the microstructure of the sample [29].The indentations (at the nanoscale testing) are useful to analyze many very thin materials, like foils or coatings [30], or to measure small parts or areas, or the surface of a part [31], by determining cross sections or individual microstructures [32] of the materials in work [33-36].

In this study were explored the influences of various combinations of grind and new material on indentation hardness and the indentation elastic modulus of parts made of ABS, PA 6.6 and POM polymers, used in the

automotive industry, through nanoindentation - G - Series Basic Hardness Modulus at a Depth method. The valuated parameters represent important engineering properties for tested materials. The hardness of a solid material is defined as a measure of its resistance to a permanent shape change, when a constant compressive force is applied on it. The deformation results through different mechanisms: indentation, cutting, scratching, mechanical wear, or bending. In the case of most polymers, the hardness is related to the plastic deformation of the surface of a material. Also, the hardness has a close relation to some other mechanical properties like: ductility, strength, and fatigue resistance; therefore, the hardness testing can be used in different industries as a fast, simple, and relatively low costs quality control method for materials [28,29]. Modulus of elasticity is defined as a measure of the stressstrain relationship. It is an essential parameter in the evaluation of the deformation response of concrete under working loads [37].

The samples tested in this work were made by combining grinding with new material in various proportions (from 0 to $100 \%$ ). The data were obtained by maintaining constant injection parameters specific to each polymer that could alter the properties determined in the study (temperature of injection, mold temperature, injection pressure, holding pressure injection, speed injection cycle time, cooling time in the mold injection, time holding, and pressure time). The hardness and the elastic modulus of the techno polymers investigated in this study appear to be influenced by the grind content $[14,26,27]$.

The increase of the grind percentage of $A B S$ (from $0 \%$ to $100 \%$ ) leads to some insignificant changes in the indentation modulus, indentation hardness, and maximum force applied to the material samples. The maximum indentation hardness was recorded at the sample with $80 \%$ grind percentage and was $0.142 \mathrm{GPa}$. The maximum indentation modulus value was also recorded at the sample with $80 \%$ grind percentage and was $2.954 \mathrm{GPa}$. The variation of grind percentage in case of ABS has the similar effect on both hardness through indentation and penetration hardness with a Shore durometer, D type [27],

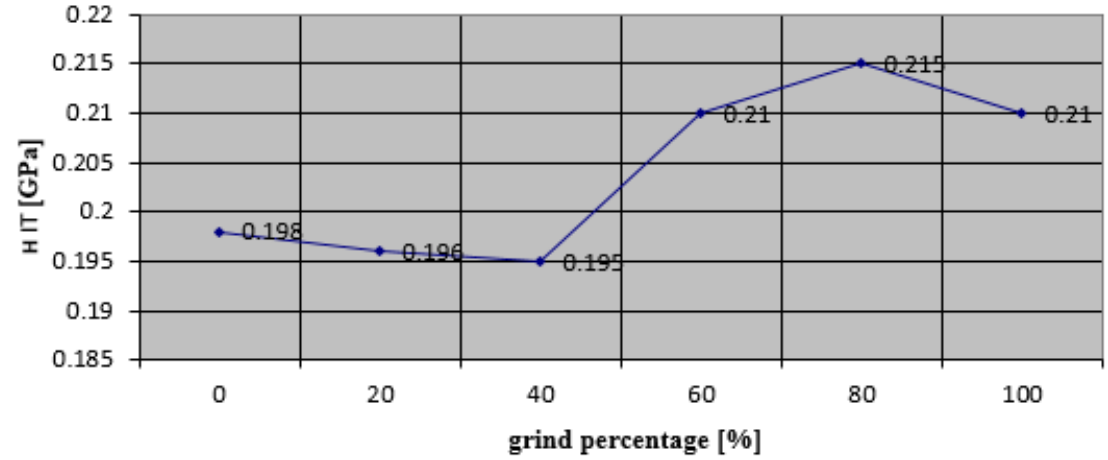

Fig. 9. The variation of the indentation hardness depending on the grind percentage, in the case of POM 
namely the increase of grind percentage leads to a slight increase of the hardness of the tested samples. These results clearly indicate that in the case of ABS, by adding grind in different percentages, the hardness of the injected piece surface can be improved.

In the case of PA 6.6, it can be noticed that an increasing in the grind percentage from 0 to $80 \%$ conducts to a slight increase of the indentation hardness. The maximum hardness of PA 6.6 is recorded at the sample with an $80 \%$ content, and it is of $0.137 \mathrm{GPa}$. The further increase of the grind percentage from 80 to $100 \%$ induces a decreasing of the indentation hardness (to $0.106 \mathrm{GPa}$ ). Adding grind in optimal proportions results in an increase in hardness of the injected piece surface, in the case of PA 6.6, with the bestresults for combined $80 \%$ grind with $20 \%$ new material.

In case of POM, it can be observed that an increasing of the grind percentage from $0 \%$ to $80 \%$ leads to an increase of the indentation modulus, indentation hardness, and maximum load force applied to the samples of tested material. The maximum hardness of polyoxymethylene POM was recorded in the case of the sample with $80 \%$ grind content, and it was of $0.215 \mathrm{GPa}$. The further increase of grind percentage from 80 to $100 \%$ leads to a decrease in indentation hardness to $0.210 \mathrm{GPa}$. In a similar way acts the indentation modulus to the variation of grind percentage change in the samples.

There is a change in the hardness of the surface of the injection molded parts after the addition of variable amounts of grinding. In the case of the three polymers tested, the maximum values of hardness were obtained in samples with a content of $80 \%$ grinding. The modulus elasticity increases with the increase in hardness, fact that corresponds to the literature data. The polymers studied are common thermoplastics, commonly used to make light, rigid and molded products [38-42].

The results obtained in this study prove the importance of the research carried out on the influence of the amount of grind reintroduced in the manufacturing process on the surface hardness and the elasticity of the products injected from ABS, PA 6.6 and POM, three of the most used techno polymers in the automotive industry.

\section{Conclusions}

As a result of this study, the data show that combining new materials with grinding materials in different proportions, specific to each type of polymer, can improve the mechanical properties of the studied techno polymers. For $A B S$, the variation in grinding content does not significantly change the hardness of the material. In the case of PA 6.6 and POM, the results show that maximum hardness is recorded in samples with $80 \%$ grind content. Reusing the thermoplastic polymer residues by grinding and reintroducing them into the technological process is an efficient way to recover large amounts of plastic waste, resulting in significant material savings and financial benefits.

Acknowledgments: We sincerely thank to SC Plastor SA Oradea and SC Capirom SRL Santandrei for their material and logistic support offered to the University of Oradea throughout the research which focused on the influence of grinding material percentage over the indentation hardness and on the indentation modulus, in the case of $A B S, P A$ and POM.

\section{References}

1.MARSAVINA, L., CERNESCU, A., LINUL, E., SCURTU, D., CHIRITA, C., Mat. Plast., 47, 2010, p. 85.
2.SERES, I., Materiale termoplastice pentru injectare, tehnologie, incercãri (Thermoplastic materials for injection, technology, tests), Ed. Imprimeriei de Vest, Oradea, Romania, 2002, pp. 92-104.

3.TROTIGNON, J.P., VERDU, J., DOBRACGINSKY, A., PIPERAUD, M., Matieres Plastiques. Structures-proprietes, Mise en ouvre, Normalisation, Ed. Nathan/AFNOR, Paris, France, 1996, pp. 85-88.

4.MANOVICIU, V., MARIES, G.R.E., Materiale compozite cu matrice organicã (Composite materials with organic matrix), Ed. University of Oradea, Oradea, Romania, 2005, pp.145-149.

5.PICHON, J.F. Injection des matieres plastiques, Dunod, Paris, France, 2001, pp.11-12.

6.FLORUS, S., OTRISAL, P., Chem. Listy, 108, 2014, p. 838.

7.OTRISAL, P., FLORUS, S., SVORC, L., BARSAN, G., MOSTEANU, D., Mat. Plast., 54, no. 4, 2017, p. 748.

8.OTRISAL, P., FLORUS, S., BARSAN, G., MOSTEANU, D., Rev. Chim.(Bucharest), 69, no. 2, 2018, p. 300.

9.OTRISAL, P., OBSEL, V., BUK, J., SVORC, L., Nanomaterials, 8., nr. 8, 2018, p. 564. https://doi.org/10.3390/nano8080564

10.CIOCA, M., CIOCA, L.-I., BURAGA, S.-C., Proceedings of the 2007 Inaugural IEEE-IES Digital ECoSystems and Technologies Conference, DEST 2007, 4233779, 2007, p. 607.

11.CIOCA, M., GHETE, A.-I., CIOCA, L.-I., GIFU, D., Appl. Mech. Mat., 371, 2013, p. 769.

12.CIOCA, L.-I., CIOCA, M., WSEAS Transactions Information Sci. Appl., 4, nr. 2, 2007, p. 303.

13.CIOCA, M., CIOCA, L.-I., 3rd IEEE International Conference on Industrial Informatics, INDIN, 1560381, 2005, p. 230.

14.MARIES, G.R.E., CHIRA, D., BUNGAU, C., COSTEA, T., MOLDOVAN, L., Mat. Plast., 54, no. 2, 2017, p. 214.

15.BUnGAU, C., GHERGHEA, I.C., PRICHICl, M., Conference: $1^{\text {st }}$ Management Conference on 20 Years After: How Management Theory Works, Book Series: Review of Management and Economic Engineering International Management Conference, Cluj-Napoca, Romania, 2010, p. 188.

16.BUNGAU, C., BLAGA, F., GHERGHEA, C., International Conference on Production Research - Regional Conference Africa, Europe and the Middle East (ICPR-AEM)/3rd International Conference on Quality and Innovation in Engineering and Management (QIEM), Cluj Napoca, Romania, 2014,p. 55.

17.SUAREZ, J.C.M., MANO, E.B., TAVARES, M.I.B., J. Appl. Polym. Sci, 78, 2000, p. 899.

18.LI, B., ZHANG, X., ZHANG, Q., CHEN, F., FU, Q., J. Appl. Polym. Sci, 113, 2009, p. 1207.

19.CURTU, I., MOTOC, D.L., Mat. Plast., 45, 2008, p. 366.

20.LILE, I. E., FREIMAN, P. C., HOSSZU, T., VASCA, E., VASCA, V., BUNGAU, S., VAIDA, L., Mat. Plast., 52, no. 2, 2015, p. 175.

21.MANZUR, A., OLAYO, R., RAMOS, E., J. Appl. Polym. Sci, 65, nr. 4, 1997, p. 677.

22.SUAREZ, J.C.M., MANO, E.B., MONTEIRO, E.E.D., TAVARES, M.I.R., J. Appl. Polym. Sci, 85, 2002, p. 886.

23.STAN, F., FETECAU, C., Composites Part B: Engineering, 47, 2013, p. 298.

24.MARIES, G.R.E., CHIRA, D., Mat. Plast., 49, 2012, p. 288.

25.GURUPRASAD, B., RAGUPATHY, A., BADRINARAYANAN, T.S., VENKATESAN, R., IJET, 2, 2012, p. 1921.

26.CHIRA, D., MARIES, G.R.E., BUNGAU, C., Mat. Plast., 52, no. 4, 2015, p. 572.

27.MARIES, G.R.E., CHIRA, D., BUNGAU, C., Mat. Plast., 52, no. 4, 2015, p. 452.

28.*** ISO 14577-1:2002, Metallic materials - Instrumented indentation test for hardness and materials parameters - Part 1: Test method.

29.BROITMAN, E., Tribol. Lett., 65, 2017, p. 23.

30.BROITMAN, E., FLORES-RUIZ, F.J., DI GIULIO, M., GONTAD, F., LORUSSO, A., PERRONE, A., J. Vac. Sci. Technol., A 34, 2016, 021505. 31.GARD, A., KARLSSON, P., KRAKHMALEV, P., BROITMAN, E., Adv. Mater. Res., 1119, 2015, p. 70.

32.KHAN, A., HUSSAIN, M., NUR, O., WILLANDER, M., BROITMAN, E., Phys. Status Solidi (A), 212, nr. 3, 2015, p. 579. 
33.BROITMAN, E., BECKER, R. DOZAKI, K., HULTMAN, L., A novel oxide characterization method of nickel base alloy 600 used in nuclear plant reactors. In: Marquis, F.D.S. (eds.) PRICM 8: Advanced Materials and Processing, Chap. 415. Wiley, Hoboken, 2013.

34.FRITEA, L., BANICA, F., COSTEA, T.O., MOLDOVAN, L., IOVAN, C., CAVALU, S., J. Electroanal. Chem., 830, 2018, p. 63. doi: 10.1016/ j.jelechem.2018.10.015

35.CAVALU, S., BANICA F., SIMON V., AKIN I., GOLLER G., Int. J. Appl. Ceram. Tec., 11, nr. 2, 2014, p. 402.

36.CAVALU, S., SIMON, V., BANICA, F., OSWALD, I., VANEA, E., AKIN, I., GOLLER, G., Studia UBB Chemia, 56, nr. 3, 2011, p. 27.

37.DHIR, R.K., GHATAORA, G.S., LYNN, C.J ., 5 - Concrete-Related Applications, Sustainable Construction Materials, Woodhead Publishing, 2017, p. 111. https://doi.org/10.1016/B978-0-08-1009871.00005-6
38.OTRISAL, P., MELICHARIK, Z., SVORC, L., BUNGAU, S., VIRCA, I., BARSAN, G., MOSTEANU, D., Mat. Plast., 55, no. 4, 2018, p. 545.

39.CARAC, A., BOSCENCU, R., DEDIU, A.V., BUNGAU, S.G., DINICA, R.M., Rev. Chim.(Bucharest), 68, no. 7, 2017, p. 1423.

40.REINHARDT, H.W., MIELICH, O., Effects of mechanical properties of ASR damaged concrete on structural design, Brittle Matrix Composites 10, Woodhead Publishing, 2012, pp. 1-9.

41.PRIKRYL, RADEK., OTRISAL, P., OBSEL, V., SVORC, L., KARKALIC, R., BUK, J., Nanomaterials, 8, nr. 9, 2018, p. 679. https://doi.org/10.3390/ nano8090679

42.OTRISAL, P., MELICHARIK, Z., SVORC, L., OANCEA, R., BARSAN, V., Mat. Plast., 55, no. 3, 2018, p. 325.

$\overline{\text { Manuscript received: } 23.12 .2018}$ 